\title{
Using Sensemaking Technique to Construct Scientific Explanations in Organizational Research
}

\author{
Everest Turyahikayo \\ Department of Public Administration and Management, Uganda Management Institute, Kampala, Uganda
}

Email address:

everestdidas@yahoo.co.uk

\section{To cite this article:}

Everest Turyahikayo. Using Sense Making Technique to Construct Scientific Explanations in Organizational Research. International Journal of Philosophy. Vol. 7, No. 4, 2019, pp. 167-172. doi: 10.11648/j.ijp.20190704.15

Received: October 3, 2019; Accepted: October 26, 2019; Published: December 12, 2019

\begin{abstract}
In the philosophy of science, an impression is created that scientific explanations are perhaps a preserve of physical and natural sciences. Although social scientists in organizational research have borrowed most modals of scientific explanations from natural scientists, they have met harsh criticism from their counterparts in the natural and physical sciences. This paper set out to explain how scientific explanations can be constructed successfully in organizational studies using modals borrowed from natural sciences. Basing on the critical literature review, the paper has successfully argued that, organizational research applies models of scientific explanations using sense making. In the case of the covering law model, it has been argued that the model connects well with sense making in organizational research in many respects since sense making recognizes explanandum in terms of organizational events that people experience in everyday life. The paper has also indicated that in the statistical-probabilistic model explanations are based on non-deductive reasoning and make it hard for the researcher to predict the explanandum with certainty except with some degree of probability. This applies in both organizational studies as well as in natural sciences. Like in the statistical probability model, causal-effect relationships can also be demonstrated statistically in organizational research. Moreover, the fact that organizational researchers have different traditions from those of 'number crunchers' does not make such traditions inferior. Lastly, the unification model portrays scientific explanations as constructed in a unified design. The paper has shown that in organizational research, unification manifests quite differently from the natural sciences. Organizations operate in unstable condition in the sense that there are so many disciplines under organizational research.
\end{abstract}

Keywords: Philosophy, Scientific Explanation, Sense Making, Organizational Research

\section{Introduction}

In the deductive philosophy of science, an impression is created that scientific explanations are perhaps a preserve of physical and natural sciences. Most scholars in the philosophy of science are bothered by how natural scientists construct scientific explanations to answer questions relating to phenomena in hard sciences [1,2]. Such issues as why light is refracted by a prism; laws of optics by Maxwell's electrodynamics; the ideal gas law by the molecular-kinetic theory are some examples of the issues natural science tries to resolve [1]. However, previous scholars have invested little effort in showing whether organizational research can borrow modals from natural sciences and apply them. Some scholars have even alleged that scientific explanations are not well defined for organizational researchers [2], an allegation refuted in this article. The main argument here is that scientific explanations can be constructed successfully in organizational studies using modals in natural sciences. It will be argued that unlike in natural sciences, organizational research applies sense making technique in order to contextualize scientific explanations.

\subsection{Conceptualizing Scientific Explanations in Organizational Research}

Scientific explanations have been conceptualized as statements of causation about how or why phenomenon occurred [4]. Such explanations relate to explicit application of theory in describing natural patterns and causal relationships for a specific situation [3] using observed facts [5]. Some early scholars in philosophy of science such as [6, 15] indicated that scientific explanations of an event or 
phenomena unveil a causal story leading to its occurrence [6]. The main focus of such explanations is to answer 'what' prescriptive questions relating to what actually happened to phenomena, as well as 'why' it happened $[7,5]$. In an attempt to describe theoretical accounts of how phenomena unfold the way they do, scientific explanations rely on what is claimed to be 'scientifically proven methodologies' regarding the content of the observations, as well as data that are part of the existing body of knowledge of their field of expertise [2, 5] Three critical elements are necessary in constructing scientific explanations. These are; a claim; evidence; and reasoning [4]. A claim is a statement that answers a scientific question; evidence is scientific data that support the claim; and reasoning is the application of the cognitive power, reflexivity and discourse in an attempt to explain the nexus between the evidence adduced and the claim [8]. The other most important element is the inference drawn from the claim-evidence-reasoning thread [4]. These elements are closely linked to the goals of constructing and defending scientific explanations. The goals are; using evidence and make sense of the phenomena; articulating scientific understandings; and convincing other scholars and practitioners [7].

\subsection{Conceptualizing Sense Making in Organizational Research}

There is no common definition of sense making in organizational research. However, most authors relate the concept to a process through which researchers create their situations and attempt to make them comprehensible to themselves $[12,9]$. In summary terms, sense making is about searching for and making sense of the information or data about phenomena [10]. To make sense out of the gathered data, researchers normally create structures in which they fit in data. This is done to make representations and arrive at an objective understanding of the phenomenon [10]. Unlike in natural sciences where non-living objects such as kinetic energy, speed and distance, chemical compositions etc dominate the subject of investigation, sense making in organizational context revolves around real life situation and centres around peoples' understanding and perceptions attached to issues being investigated $[11,12]$. The perceptions and understanding held by people prevail in a recursive relationship with the object of research [13]. This recursive relationship has the power to apply even retrospective processes [12], an aspect to be revisited later in this paper.

Researchers have been bothered by three aspects in relation to sense making. First, the aspect of when sense making is invoked; second, where it is situated in organizational setting, and third, the role of evidence in sense making $[13,12]$. The main entry point for sense making is when organizational members encounter ambiguous situations. They set out to seek for an explanation through a carefully thought methodology involving data collection and interpretation [14] about the ambiguous event in order to make sense of the story [11]. From the preceding, we may infer that sensemaking is created and situated in the organizational routine practices, processes and systems as manifested in interactions and actions within organizations [9]. The third aspect relates to evidence which is used to persuade the reader about the investigated phenomena [7]. Organizational research relies heavily on scientific evidence. The implication here is that sense making, and scientific explanations are intertwined in organizational research. The rigour organizational researchers go through in trying to make sense of the phenomena can be compared with the same rigour in astronomy, biochemistry or physics. This assertion is supported in the proceeding sections.

\section{Constructing Scientific Explanations Using Sense Making in Organizational Research}

In organizational research, it is possible to use models from natural sciences in constructing scientific explanations as alluded to in the introductory part of this paper. The most common models are covering law model also known as Deductive-Nomological (D-N model) [15] and the related S$\mathrm{R}$ model [6] the probabilistic statistical model [2]; the causation model [2]; and the unification model [16]. In the following discussion, these models are explicated in the organizational research perspective connecting each of them to sense making.

\subsection{Covering Law Model of Scientific Explanations and Sense Making}

The covering law model contends that scientific explanation can be divided into two components; first, the sentences describing the phenomenon to be explained also known as explanandum; second, the class of those sentences adduced to account for the phenomenon also known as explanans [3]. In other words, the reasoning behind the scientific explanation is deductively valid hence the explanandum could have been predicted with certainty [5]. However, for the prediction to be successful, there must be a logical consequence of the explanans to guarantee logical deduction of the explanandum from the information contained in the explanans $[1,17]$. As $[15,5]$ indicate, for the explanation to qualify as a scientific, it should be made explicit that the latter facts are the cause of the former.

The covering law model connects well with sense making in organizational research in many respects. Sense making recognizes explanandum in terms of organizational events that people experience in everyday life [11]. Organizational members usually create meaning from the daily experience, as well as of the organizational cultural context in which they relate [12]. Organizational research commences when people make claims about these events and seek scientific evidence to interpret the event and draw logical conclusions $[9,11]$. Moreover, researchers tend to develop hypotheses about the object of study which can be falsified or confirmed on the basis of interpreted data [18]. Unlike in 
natural sciences where scientific explanations have to be grounded in the phenomena, in organizational research the aim is to show why the event occurred in terms of prior events and laws [19]. The acceptability of arguments raised in organizational research depends on the logical coherence in deductive and inductive reasoning about the phenomenon $[2,20]$.

\subsection{Statistical Probabilistic Model of Scientific Explanations and Sense Making}

While the covering law model lays emphasis on explanandum-explanans nexus, the statistical probabilistic model also known as Inductive-Statistical (I-S) model presupposes general laws that are of statistical nature [15]. Scientific explanations emerge from the statistical inferences generated from quantitative data [5]. The extent to which the research results will be accepted depends largely on the degree of coherence between explanation and data [2] rather than from strictly universal form. Contrary to the D-N model where explanatory arguments are deductive, the resulting explanatory arguments under this model are inductive in character [15].

The main reason behind the statistical-probabilistic model is that explanations are based on non-deductive reasoning and make it hard for the researcher to predict the explanandum with certainty except with some degree of probability [5]. One of the main features of the I-S model is the premise of relevance [6]. Relevance in the face of the decision makers or researchers who have to make sense of the data in light of the prevailing events being studied [3]. In order to enhance relevance, data is trimmed and categorized in a more meaningful design [21].

How does the statistical-probabilistic model mix with the sense making perspective in organizational research? Premafacie, statistical inferences connote value-free observations. Such observations are void of feelings, perceptions and subjective experiences as we know them in organizational settings. However, scholars have indicated that constructs in the hard sciences have mobility power into the social realm [22]. Yet, the transfer of such constructs is partial in nature and relates to components that have efficacy in organizational research. This is because organizational phenomena unlike in hard disciplines do not render themselves to controllable observations [18]. Yet, many organizational researchers since the time of Likert have developed scales to statistically measure human perceptions, experiences and emotions. This is done following the rules of scientific inferences [22]. In some cases depending on the research question, scholars in organizational research can apply a mixed-method approach in which case both qualitative and quantitative techniques are applied to enhance complementarity and triangulation of data [23]. Sense making then becomes part and parcel of the analyzed and interpreted data. This is because the socially constructed meanings attached to phenomena and the researcher are inseparable $[12,11]$.

\subsection{The Causal Model of Scientific Explanations and Sense Making}

According to the causal model, scientific explanations are constructed on the basis of cause and effect relationship [24]. This relationship is based on the evidence and logical arguments [7]. Like in the statistical probability model, causal-effect relationships can also be demonstrated statistically. One of the proponents of this view is [6] who argued that researchers can construct theories of probabilistic causality. Unlike in the deductive models, most scholars in the philosophy of science claim that probabilistic causality is applicable in situations where cause-effect attribution cannot be ascertained with certainty $[15,6]$. Further, they claim that research processes in which cause-effect relationship is imperfect have been rudely labelled 'pseudo-processes' [6, 24] as opposed to causal processes. Labelling such as 'pseudo-processes' is nothing far from stereotypes by natural scientists. The fact that organizational researchers have different traditions from those of 'number crunchers' does not make such traditions inferior. Organizational research is conducted in an unstable and volatile environment in which organizations operate. This explains why organizational researchers endeavour to focus on rigour and coherence while establishing causation [2].

Contemplation on scientific explanations in organizational research should consider two fundamental factors. First, organizational research centres around people as subject of investigation. Psychology has explained that during interaction, people decide "which self is appropriate and which self to present to others [9]. The unpredictive nature of human behaviour exacerbates the researchers' dilemma in attempting to construct scientific explanations in organizational research. [25]. Second, the pluralistic nature of causation in organizational science implies a multiplicity of not only epistemological assumptions but also a diversity of research designs and methodological prescriptions [26]. How then should researchers arrive on causality while constructing scientific explanations in organizational research?

In organizational research just like in most social science disciplines, the common agreement is that causality does not surrender itself to observation [24]. Scientific explanations have to be constructed through manipulating some conditions that enable the inference that a causal relationship exists [23]. Organizational researchers also must make sense of the statistical data to draw scientifically acceptable inferences. Another challenge an organizational scientist grapples with relates to drawing a distinction between correlation and causation. Seasoned organizational researchers are aware that correlation leads to causation and the two constructs are different. Usually, when researchers establish correlations between independent and dependent variables, they base on the coefficient values to ascertain the degree of causation using regression tests [27]. It is common to consider multiple regressions because no single factor can explain cause and effect in organizational phenomena. Even in cases where regressions are performed, the list of factors manipulated is 
less exhaustive. This explains why generalizations in organizational studies is applied on the target population from which the sample is drawn as opposed to universal deductive generations in natural sciences [28].

\subsection{Unification Model of Scientific Explanations and Sensemaking}

The unification model portrays scientific explanations as constructed in a unified design. Scientific explanations consist in demonstrating similarity among disparate phenomena [6]. The model attempts to show that explanandum in the sense of [15] fits well into a unifying system of laws. For instance, in natural sciences, scientific explanations fit into the respective laws such as the Newton's laws of motion on why the apple falls directly to the ground or why the moon revolves about the earth in apparent perpetuity [30]. How does unification explain understanding and comprehending science built under this model? According to [13], the intelligibility of scientific explanations is enhanced by the degree to which an idea connects phenomena. This connection should be in conformance to other accepted explanations [5].

In organizational research, unification manifests quite differently from the natural sciences [30]. Organizations operate in unstable condition in the sense that there are so many disciplines under organizational research. Most disciplines break away from their roots before developing a strong theoretical foundation leading to the fragmentation trap [11]. Some of these disciplines include human resource management, organizational development, knowledge management, public administration to mention but a few. In instances where a discipline is unstable, unification is in small portions [27]. Another challenge to unification in organizational research relates to the limitations of human cognitive power in predicting unobservable phenomena. Organizational research relies heavily on stories people tend to share in accordance with their will. As [11] revealed earlier, such stories may be shaped by inadequate information or distorted experiences. In order to control imperfections likely to arise from unstable and idiosyncratic understanding as alleged [31,9], large sums of data are collected, analyzed and interpreted so as to draw acceptable inferences on the target population.

The discussion has demonstrated the connection between scientific explanations and sense making in organizational research. The conceptual model below summarizes such a connection as a basis for the discussion and implications.

The model shows arrows moving from the unification model upwards. By implication, the unification model applies to all the three models. As $[6,15]$ indicated, scientific explanations must be unified. As such, organizational researcher intending to construct such explanations based on either covering law model, statistical or causal models need to put this fact into consideration. In organizational research, models of scientific explanations and sense making are intertwined in order to generate theory about phenomena.

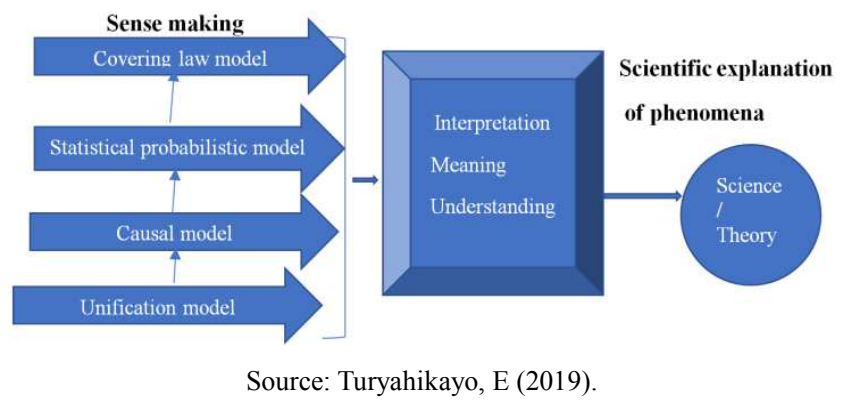

Figure 1. Scientific explanation-sense making nexus in organizational research.

\section{Discussion and Implications for Researchers in Organizational Science}

Prior studies have indicated to some extent, the connection between the models of scientific explanations and sense making in organizational research. What seems clear though is the friction apparent between natural scientists and organizational scientists regarding the efficacy of the covering law model in non-science disciplines such as organization management. Specifically, there are misconceptions to the effect that deductive arguments in which conclusions flow from true premises should be a preserve of natural science $[32,34]$ The agreement shared among social and natural scientists is that theory construction on the basis of deductive reasoning cannot yield predictive power [34]. This view is also supported by [35] who claims that only quantifiable predictions should build strong theoretical bases. Whereas these deterministic arguments may be sound depending on the side you view them, their claim that strong theoretical foundations as in natural sciences constitute acceptable scientific explanations is rather an over-simplification. Since time immemorial, many theories in both natural and social sciences have been falsified, revised and dropped. This change has been due to emerging of new evidence or due to inevitable social, contextual and conceptual changes in academic disciplines. Deductive arguments are a product of sense making involving inductive sentiments and human limitations regardless of the discipline of inquiry.

In respect of statistical probabilistic model, literature has shown that sense making is applied on inductive arguments to construct scientific explanations. Much as inductive reasoning has been labelled riskier than deductive reasoning because of its limitation in accessing enough data from which to generalize, [41, 36], and that it lacks justification [35], its form and substance enhances meaning and understanding of organizational phenomena [32] out of quantitative and qualitative data [7]. Moreover, looking deeper into the potential and nature of statistical probability model, one finds that richer qualitative data can be gathered using interviews, observation and focussed group discussions to make sense of the themes emerging. In mixed methods studies where qualitative and quantitative approaches combine, these themes are evaluated alongside their quantitative counter- 
parts in theory construction. Indeed, organizational researchers have used this technique to construct scientific explanations and build numerous theories such as scientific management theory, human relations theory, the theory of bureaucracy, contingency theory, institutional theory among others. All these theories have existed unchallenged for centuries, and together they fall within organizational science. Therefore, what counts is not mere big data advocated for in the covering law model but how such data is utilized in constructing scientific explanations.

The causal link model has its roots in organizational research. Evidence from the literature has shown that humans have evolved causal thinking as a means of survival and innovation for decades [36]. The cause-effect relationship results from objective validity of empirical judgements. In constructing scientific explanations using the principle of causality, researchers are able to distinguish causal effects from mere subjective associations [37, 36]. In constructing scientific explanations, the cause-effect relationship among the phenomena variables can only be ascertained through sense making. This is because, values and figures used to portray causal linkages are inherently meaningless unless it is determined that they are statistically significant [38]. Moreover, in as much as statistical significance has a formal criterion, it remains a creature of human judgement and interpretation. Quite often, organizational researchers identify phenomena in terms of predictor variable and variable of measurement. They go further to test the cause-effect relationships between these variables. It is common to base the studies on theories as well as quantitative techniques.

Unification as the last model in constructing scientific explanations has not been paid detailed attention to in both natural science and organizational based studies. However, the scanty literature available labels blame on organizational research for ignoring the interrelationships among the various components of science [41]. In addition, natural scientists claim that the multidisciplinary nature of organizational research imply diverse ontologies and epistemological presuppositions hence making unification impossible [39]. However, organizational research has to deal with unstable and fluid phenomena in which case theories are not only multiple but also transient calling for their synthetic integration within the organizational science field [40]. Sense making is at the centre of this synthetic integration of theories and ontologies.

\section{Contribution of this Paper}

This conceptual paper appears to be one of the few publications in showing how organizational research can borrow and apply models traditionally considered as a preserve of natural sciences using sense making. The paper contributes to the current understanding of theory construction or the crafting of scientific explanations using such models. The debate ignited in this article will surely contribute to the forging of a peaceful co-existence between organizational researchers and natural scientists, who have always despised each other's competence in conducting scientific studies.

\section{Conclusion}

This paper has argued that scientific explanations can be constructed in organizational science contrary to the beliefs held by natural scientists. The difficulty in designing social experiments in organizational research should be perceived as a complexity to deal with rather than being seen as an obstacle [41]. The ability of the researcher to constantly switch between the induction and deduction modes of reasoning during construction of scientific explanation [42] is what makes organizational research sound and edifying to researchers and practitioners. The insights produced by a mixture of qualitative and quantitative data as subjected to sense making make scientific explanations in organizational research more plausible [43]. While considering the concerns raised by natural scientists about the need for scientific rigour, we cannot lose sight of the fact that phenomena is perceived with various lenses. Thus, not all differences in belief, perception and philosophical tradition will be resolved but rather accommodated [13]. Sense making as a tool will enhance reconciliation of deductive-inductive traditions by recognizing the role and importance of each [13] so as to guarantee progress in organizational science.

\section{References}

[1] M. Friedman, "Explanation and Scientific Understanding," J. Philos., vol. 71, no. 1, p. 5, 2006.

[2] M. Braaten and M. Windschitl, "Working toward a stronger conceptualization of scientific explanation for science education," Sci. Educ., vol. 95, no. 4, pp. 639-669, 2011.

[3] J.-X. Yao, Y.-Y. Guo, and K. Neumann, "Towards a hypothetical learning progression of scientific explanation," Asia-Pacific Sci. Educ., vol. 2, no. 1, 2016.

[4] C. C. Hsu, C. H. Chiu, C. H. Lin, and T. I. Wang, "Enhancing skill in constructing scientific explanations using a structured argumentation scaffold in scientific inquiry," Comput. Educ., vol. 91, pp. 46-59, 2015.

[5] J. H. M. Wagemans, "Argumentative Patterns for Justifying Scientific Explanations," Argumentation, vol. 30, no. 1, pp. 97-108, 2016.

[6] W. C. Salmon, "Scientific Explanation: Three Basic Conceptions Wesley C. Salmon PSA: Proceedings of the Biennial Meeting of the Philosophy of Science Association, Vol. 1984, Volume Two: Symposia and Invited Papers. (1984), pp. 293-305.," Philos. Sci., vol. 1984, pp. 293-305, 1984.

[7] L. K. Berland and B. J. Reiser, "Making sense of argumentation and explanation," Sci. Educ., vol. 93, no. 1, pp. $26-55,2009$.

[8] A. M. Novak and D. F. Treagust, "Adjusting claims as new evidence emerges: Do students incorporate new evidence into their scientific explanations?" J. Res. Sci. Teach., vol. 55, no. 4, pp. 526-549, 2018. 
[9] F. Allard-poesi and F. Allard-poesi, "The Paradox of Sensemaking in Organizational Analysis To cite this version: HAL Id: hal-01251211 The Paradox of Sensemaking in Organizational Analysis," vol. 12, no. 2, pp. 169-196, 2016.

[10] P. Zhang, D. Soergel, J. L. Klavans, and D. W. Oard, "Extending sense-making models with ideas from cognition and learning theories," Proc. Am. Soc. Inf. Sci. Technol., vol. 45 , no. 1 , pp. 23-23, 2009.

[11] K. E. Weick, K. M. Sutcliffe, and D. Obstfeld, "Organizing and the Process of Sensemaking," Organ. Sci., vol. 16, no. 4, pp. 409-421, 2005.

[12] M. de L. Borges and C. R. Gonçalo, "Learning process promoted by sensemaking and trust: a study related to unexpected events," Cad. EBAPE. BR, vol. 8, no. 2, pp. 260 277, 2010.

[13] N. K. Agarwal, "Making sense of sense-making: tracing the history and development of Dervin's Sense-Making Methodology," Int. Perspect. Hist. Inf. Sci. Technol. Proc. ASIS \& T 2012 Pre-Conference Hist. ASIS\&T Inf. Sci. Technol., p. 13, 2012.

[14] S. Maitlis and M. Christianson, "Sensemaking in Organizations: Taking Stock and Moving Forward," Acad. Manag. Ann., vol. 8, no. 1, pp. 57-125, 2014.

[15] C. G. Hempel, "Two Basic Types of Scientific Explanation / Inductive-Statistical Explanation," Philos. Sci. Cent. Issues, pp. 9-19, 1998.

[16] M. Strevens, "An argument against the unification account of explanation," no. December, pp. 1-29, 1999.

[17] H. Veatch, "Aspects of Scientific Explanation and Other Essays in the Philosophy of Science. Carl G. Hempel," Philos. Sci., vol. 37, no. 2, pp. 312-314, 2002.

[18] A. Bhattacherjee, Introduction to Research, Social Science Research: Principles, Methods, and Practices. 2012.

[19] E. Miller, "Humean scientific explanation," Philos. Stud., vol. 172, no. 5, pp. 1311-1332, 2015.

[20] A. Potochnik, "Scienti fi c Explanation: Putting Communication First," vol. 83, no. December, pp. 721-732, 2016.

[21] M. Namvar, J. L. Cybulski, C. S. C. Phang, Y. S. Ee, and K. T. L. Tan, "Simplifying sensemaking: Concept, process, strengths, shortcomings, and ways forward for information systems in contemporary business environments," Australas. J. Inf. Syst., vol. 22, 2018.

[22] I. Jarvie, J. Zamora-Bonilla, and D. Steel, "Causality, Causal Models, and Social Mechanisms," SAGE Handb. Philos. Soc. Sci., pp. 288-304, 2014.

[23] L. J. Rennie, "Dealing with Problems of Causality in Impact Studies," pp. 1-6, 2014.

[24] P. Thagard, "Theory Evaluation," Comput. Philos. Sci., pp. $3-$ 23, 2018.

[25] K. Weber and M. A. Glynn, "Making sense with institutions: Context, thought and action in Karl Weick's theory," Organ. Stud., vol. 27, no. 11, pp. 1639-1660, 2006.

[26] J. Gerring, Causation: A unified framework for the social sciences, vol. 17 , no. 2. 2005.
[27] A. Sliva, S. N. Reilly, R. Casstevens, and J. Chamberlain, "Tools for Validating Causal and Predictive Claims in Social Science Models," Procedia Manuf., vol. 3, no. Ahfe, pp. 3925-3932, 2015.

[28] A. Gelman and M. Betancourt, "Does quantum uncertainty have a place in everyday applied statistics?" Behav. Brain Sci., vol. 36, no. 3, p. 285, 2013.

[29] B. W. Salmon, "Scientific Explanation- Causation and Unification,” Philos. Sci., vol. 41, no. 0102458, pp. 40-41, 2005.

[30] C. D. Green and C. D. Green, "Review of General Psychology Why Psychology Isn' t Unified, and Probably Never Will Be Why Psychology Isn' t Unified, and Probably Never Will Be," vol. 19, no. 3, pp. 207-214, 2015.

[31] T. Lynam and C. Fletcher, "Sensemaking: A complexity perspective," Ecol. Soc., vol. 20, no. 1, 2015.

[32] S. E. Woo, E. H. O'Boyle, and P. E. Spector, "Best practices in developing, conducting, and evaluating inductive research," Hum. Resour. Manag. Rev., vol. 27, no. 2, pp. 255-264, 2017.

[33] M. Coccia, "Methods of Inquiry in Social Sciences: An Introduction," Ssrn, no. 27, 2018.

[34] J. Woiceshyn and U. Daellenbach, "Evaluating inductive vs deductive research in management studies," Qual. Res. Organ. Manag. An Int. J., vol. 13, no. 2, pp. 183-195, 2018.

[35] R. J. Ormerod, "Rational inference: Deductive, inductive and probabilistic thinking," J. Oper. Res. Soc., vol. 61, no. 8, pp. 1207-1223, 2010.

[36] P. Lanier, "Frameworks of Causal Inference for Improving Intervention, Prediction, and Imagination in Family Violence Research: a Commentary on Rose (2018)," J. Fam. Violence, 2019.

[37] A. Sobrino, J. A. Olivas, and C. Puente, "Causality and imperfect causality from texts: A frame for causality in social sciences.” 2010 IEEE World Congr. Comput. Intell. WCCI 2010,2010

[38] S. L. Bressler and A. K. Seth, "Wiener-Granger Causality: A well established methodology," Neuroimage, vol. 58, no. 2, pp. 323-329, 2011.

[39] J. Persson, A. Hornborg, L. Olsson, and H. Thorén, "Toward an alternative dialogue between the social and natural sciences," Ecol. Soc., vol. 23, no. 4, 2018.

[40] K. Wu, P. Marijuan, and Z. Wang, "A Dialogue about the Nature and Unification of Information Science and Information Philosophy," Proceedings, vol. 1, no. 3, p. 72, 2017.

[41] D. J. Watts, "Should social science be more solutionoriented?" Nat. Hum. Behav. vol. 1, no. 1, 2017.

[42] M. R. Armat, A. Assarroudi, M. Rad, H. Sharifi, and A. Heydari, "Inductive and deductive: Ambiguous labels in qualitative content analysis," Qual. Rep., vol. 23, no. 1, pp. 219-221, 2018.

[43] T. Azungah, "Qualitative research: deductive and inductive approaches to data analysis," Qual. Res. J., vol. 18, no. 4, pp. 383-400, 2018. 